\title{
Efeito da pomada de copaíba $20 \%$ em lesões traumáticas na derme de suínos
}

\author{
Effect of copaiba ointment $20 \%$ on traumatic injuries to pigs' dermis
}

\section{Efecto de la pomada de copaiba $20 \%$ sobre lesiones traumáticas en la dermis de cerdos}

Jorge Ayrton Araujo Cansian ${ }^{1}$, Ricardo Zanella ${ }^{1 *}$, Juliano Oliveira da Cruz ${ }^{1}$, Giovana Ciacci Zanella ${ }^{1}$, Franciele Fogali Rosa ${ }^{1}$, Rubens Rodriguez ${ }^{2}$, Eraldo Lourenso Zanella ${ }^{1}$.

\section{RESUMO}

Objetivo: Avaliar o efeito do uso de pomada de copaíba $20 \%$ na recuperação de lesões traumáticas causadas por procedimentos minimamente invasivos na epiderme de suínos. Métodos: cinco fêmeas suínas com 60 dias de idade receberam aplicação tópica da pomada de Cobaíba na dose de $2 \mathrm{mg}$ por aplicação no lado cervical esquerdo por 14 dias consecutivos, após dermoabrasão. No lado cervical direito foi realizado também a dermoabrasão, porém não foi aplicado nada. No $14^{\circ}$ dia foi realizado a biópsia por punch de $5 \mathrm{~mm}$, e foi aplicado por mais sete dias a pomada de Copaíba seguido de um novo punch no dia $21^{\circ}$. Durante os 21 dias, foi verificado a enduração e hiperemia tecidual e, após a coleta, as amostras foram enviadas para avaliação histomorfológica. Diferenças foram identificadas se $\mathrm{P}<0.05$ entre paramêtros aferidos no lado com e sem Copaiba. Resultados: Diferenças foram encontradas somente no $21^{\circ}$ dia, entre o número de vasos sanguíneos, células de defesa (eosinófilos, neutrófilos e plasmócitos) e a fibrose tecidual entre o grupo tratado e não tratado $(\mathrm{P}<0.01)$. Conclusão: A pomada de Copaiba mostrou-se ser benéfica na cicatrização tecidual em suínos com lesões minimamente invasivas.

Palavras-chave: Copaíba, Regeneração, Dermoabrasão.

\begin{abstract}
Objective: The objective of our work was to evaluate the effect of the use of copaiba ointment $20 \%$ in the recovery of traumatic injuries caused by minimally invasive procedures in the swine epidermis. Methods: Five female pigs with 60 days of age received topical application of Cobaíba ointment at a dose of $2 \mathrm{mg}$ per application on the left cervical side for 14 consecutive days, after dermo-abrasion. Dermo-abrasion was also performed on the right cervical side, but nothing was applied. On the 14th day, a biopsy was performed using a $5 \mathrm{~mm}$ punch, and the Copaiba ointment was applied for seven days followed by a new punch on the 21st. During 21 days, induration and tissue hyperemia were verified, and after biopsy, the samples were sent for histomorphological evaluation, differences were identified if $P<0.05$ between parameters measured on the side with or without Copaiba. Results: Differences were found only on the 21st day, between the number of blood vessels, inflammatory cells (eosinophils, neutrophils and plasma cells) and tissue fibrosis between the group treated with and without copaiba $(P<0.01)$. Conclusion: Copaiba ointment has been shown to be beneficial in tissue healing in pigs with minimally invasive lesions.
\end{abstract}

Keywords: Copaiba, Regeneration, Dermo-abrasion.

\section{RESUMEN}

Objetivo: El objetivo de nuestro trabajo fue evaluar el efecto del uso de pomada de copaiba $20 \%$ en la recuperación de lesiones traumáticas causadas por procedimientos mínimamente invasivos en la epidermis porcina. Métodos: Cinco cerdos con 60 días de edad recibieron aplicación tópica de pomada de Cobaíba a dosis de $2 \mathrm{mg}$ por aplicación en el lado cervical izquierdo durante 14 días consecutivos, después de la dermoabrasión. También se realizó dermoabrasión en el lado cervical derecho, pero no se aplicó la pomada. El día 14 se realizó una biopsia con un punch de $5 \mathrm{~mm}$ y se aplicó la pomada de Copaíba por otros siete días

1 Universidade de Passo Fundo, Passo Fundo - RS. *E-mail: ricardozanella@upf.br

2 Instituto de Patologia de Passo Fundo, Passo Fundo - RS. 
seguidos de un nuevo punch el día 21. Durante los 21 días se verificó induración e hiperemia tisular, y luego se hizo biopsias y las muestras fueron enviadas para evaluación histomorfológica. Se identificaron diferencias si $\mathrm{P}<0.05$ entre parámetros medidos del lado con y sin Copaíba. Resultados: Se encontraron diferencias solo en el día 21, entre el número de vasos sanguíneos, células de defensa (eosinófilos, neutrófilos y células plasmáticas) y fibrosis tisular entre el grupo tratado con y sin copaíba $(P<0,01)$. Conclusión: Se ha demostrado que la pomada de Copaíba es beneficiosa en la cicatrización de tejidos en cerdos con lesiones mínimamente invasivas.

Palavras clave: Copaiba, Regeneración, Dermoabrasión.

\section{INTRODUÇÃO}

Há milênios o ser humano vem desenvolvendo técnicas como "lixamento" de pele e tecidos com o intuito de melhorar a performance de beleza além de serem associados a fatores culturais em tribos aborígenes da Austrália, Oceania, África e Brasil (ESTEVÃO LRM, et al., 2009). Estes procedimentos acabam causando lesões teciduais e consequentemente estimulando a cicatrização dos mesmos (ALMEIDA MR, et al., 2012). As lesões teciduais ocorrem com frequência e o processo de reparação, restauração e recuperação fazem parte da própria existência celular, com seus mecanismos fisiológicos de reação inflamatória e processos angiogênicos naturais (ALMEIDA MR, et al., 2012).

A microdermoabrasão é um procedimento muito utilizado com o objetivo de esfoliação dérmica, promovendo uma leve lesão tecidual superficial, removendo as células mortas e favorecendo assim a remodelação das cicatrizes através de reestruturação do colágeno e fibroblastos, sendo indicada para correções de diferentes alterações teciduais associadas aimperfeições da pele, além de remover pequenas estrias, suavizar rugas, clarear manchas pigmentares, eliminar cicatrizes hipertróficas e tratar rinofima (ALMEIDA MR, et al., 2012).

O seu uso em procedimentos cirúrgicos e sua padronização como uma metodologia cientifica é recente. Em meados do século $X X$, pesquisadores aprimoraram essas técnicas e difundiram este conhecimento entre os cirurgiões auxiliando o aproveitamento sistemático de tecidos adjacentes a áreas afetadas com difícil resolução (PAIVA LA, et al., 2002). Esta técnica, pode ser realizada com o uso de cremes específicos ou com o uso de lixas de cristais, conduzindo a fricção no local desejado, por alguns segundos ou até com o uso de um esmeril (PAIVA LA, et al., 2002).

Os procedimentos de ressurfing com microdermoabrasão estimulam a remoção de células mortas. São considerados simples e, portanto, utilizados em intervenções minimamente invasivas nas clínicas estéticas por técnicos habilitados e por cirurgiões dermatológicos, não necessitando de preparos especiais ou grande experiência cirúrgica. Outro procedimento que leva às lesões teciduais são os punchs biopsia. Estas formas de lesões histopatológicas de baixa complexidade e relativamente simples são realizadas sem sequelas e complicações e tem como principais características o baixo custo e o grande benefício clínico sendo realizados ambulatorialmente (PALHETA CSA, et al., 2017; AMORIM JL, et al., 2017).

O uso dos derivados de planta Copaifera langdorffi, tem demonstrado ser eficaz pela rápida recuperação e regeneração tecidual devido aos seus mecanismos inibidores de oxido nítrico, estimuladores de citocinas, fatores de crescimento, angiogênese tecidual, estimulação da produção de colágenos e fibroblastos locais, em animais experimentais (VEIGA-JUNIOR VF, et al., 2007; CASCON V e GILBERT B, 2000). O uso deste composto químico fitoterápico e fármacos que estimulam a angiogênese é bastante preconizada e utilizada para aumentar a viabilidade de retalhos miocutâneos de ratos (GUSHIKEN LFS, et al.,2017; SOUZA BARBOSA PC, et al., 2013; ALMEIDA MR, et al., 2012).

A pomada de Cobaíba $20 \%$ é confeccionada através de óleo extraído de árvores do gênero Copaífera da família Fabaceae-caesalpinioideae (DIAS-DA-SILVA MA, et al., 2013; MARTINS-DA-SILVA RCV, et al., 2008). Há descrição de estudos com pomada de copaíba de diversas maneiras comprovando a sua ação 
sobre as fibras colágenas, estimulação de produção de fibroblastos e auxilio na velocidade de regeneração tecidual, diminuindo a morbidade e melhorando a qualidade de vida dos pacientes (ALMEIDA MR, et al., 2012).

O objetivo do nosso trabalho foi de avaliar o efeito da pomada de copaíba $20 \%$ na cicatrização tecidual, avaliando as alterações biométricas, histomorfológicas em microdermoabrasão e biópsias com punch em epiderme de suínos.

\section{MÉTODOS}

Este trabalho seguiu as orientações padrão do Colégio Brasileiro de Experimentação Animal (COBEA) e obteve-se aprovação da Comissão de Ética no Uso de Animais (CEUA) da Universidade de Passo Fundo (UPF) em 21/03/2019 sob número de protocolo № 006/2019.

Para este projeto, foram utilizadas cinco fêmeas suínas (Sus scrofa domesticus) cruza Moura/Comercial, com idade de 60 dias e peso médio de $23 \mathrm{~kg}$, provenientes do mantenedouro do Centro de Extensão e Pesquisa Agropecuária (CEPAGRO) da Universidade de Passo Fundo, do mesmo acasalamento sendo eles irmãos inteiros, para minimizar a variabilidade genética individual em resposta ao tratamento. Os animais foram mantidos em baias coletivas de acordo com as recomendações técnicas para este cruzamento, recebendo água ad libitum e ração balanceada, de acordo com a idade e peso dos animais em intervalos de 8 horas. Os animais foram selecionados aleatoriamente e identificados com números individuais. No primeiro dia, d1 do experimento, realizou-se uma dermoabrasão na região cervical lateral direita e esquerda entre o lobo inferior da orelha e a cintura escapular do membro anterior. O processo de microdermoabrasão ou escarificação é uma lesão mínima na epiderme e algumas vezes na derme e tecido celular subcutâneo.

Este trauma foi induzido após a realização de uma tricotomia local com um aparelho de barbear, seguido pela dermoabrasão com o uso de uma lixa número 5 em tubo de ensaio, com movimentos antero-posterior e supero-inferior e com tamanho de 10 centímetros, numa profundidade de 0,2 milímetro, suficiente para apenas escarificar o local, sem causar o sangramento.

No lado esquerdo foi realizada a aplicação de pomada de copaíba 20\% diariamente por 14 dias após a realização da dermoabrasão. O lado direito serviu como controle onde foi somente realizado a dermoabrasão sem aplicação de nenhum fármaco. A pomada de copaíba $20 \%$ foi obtida em farmácia de manipulação Natufarma ${ }^{\circledR}$. A pomada foi emulsificada com o uso de emolientes e diluentes a base de Polietilenoglicol e foram acondicionadas em recipientes contendo 20 gramas deste produto.

No dia 14 foram realizadas biópsias teciduais com punch cirúrgico de $5 \mathrm{~mm}$ no local de dermabrasão de ambos os lados. As amostras foram fixadas em formol tamponado a $10 \%$ e enviadas para a avaliação histomorfológica. Após esta coleta inicial, seguiu-se a aplicação de copaíba diariamente por mais sete dias, e no dia 21 foi realizada uma nova biopsia com punch de 5 milímetros bilateral e estudo histomorfológico.

Durante as aplicações foram verificadas a enduração e a hiperemia, usando tabela tipo gabarito triangular com régua milimetrada em seu quadro interno permitindo avaliação métrica local. Durante os 21 dias do experimento, os animais foram fotografados com câmera digital, com distância focal padronizada em 50 centímetros. Essas fotografias foram digitalizadas com demarcação de área da aplicação da pomada e da área da dermoabrasão e padronizadas. Foram realizadas biópsias da pele, coletadas da porção superior (12 horas do relógio analógico), do orifício triangular do gabarito em porção inferior (6 horas), porção proximal do pavilhão auricular (11 horas) e porção distal junto do ângulo da omoplata esquerda (3 horas).

As biópsias da pele foram coletadas no $14^{\circ}$ dia e $21^{\circ}$ dia e colocadas em frascos de $10 \mathrm{ml}$ contendo formol tamponado a $10 \%$. As amostras foram catalogadas e identificadas individualmente por números respectivos a cada suíno e encaminhadas para processamento e análise histomorfológica. Posteriormente as amostras foram desidratadas com etanol e xilol, para diafanização e incluídos em parafina, seccionados em cortes de cinco micras e coradas com hematoxilina e eosina. Para avaliação da fibrose foi utilizada a coloração de tricrômica de Masson. Foram quantificados vasos, fibroblastos, fibras colágenas, neutrófilos, linfócitos, plasmócitos, eosinófilos, edema e fibroses locais. 
A biometria animal ocorreu conforme coleta padrão de dados semióticos e clínicos, com dados obtidos em fita métrica com medidas centimétricas de zero até 16 centímetros, suíno por suíno, no período de 1 a 21 dias. Os suínos foram pesados e medidos, antes e após o experimento. Parâmetros tais como coloração, sensação térmica, rubor e mensuração das áreas enduradas foram obtidas e armazenadas no programa Excel, catalogando a área por centímetro quadrado. Comparações entre as médias dos parâmetros avaliados entre o lado tratado e o lado controle de cada animal foram realizadas com o teste t de Student usando 0 programa estatístico R. Significância foi considerada se $\mathrm{P}<0,05$.

\section{RESULTADOS}

Na primeira fase do experimento a média da reação inflamatória nos primeiros três dias foram semelhantes em todos os animais $(P>0,05)$. Foi encontrada uma diferença entre a velocidade de recuperação do lado tratado com copaíba quando comparado com o lado não tratado $(P<0,05)$. No sétimo dia, as lesões por dermoabrasão do lado tratado, resultaram em uma diminuição em $30 \%$ da área. Ainda, no lado tratado as lesões diminuíram em $20 \%$ no $10^{\circ}$ dia e $10 \%$ no $14^{\circ}$ dia, quando foram coletados materiais para a segunda fase.

Lesão por dermoabrasão, sendo superficial, analisada do $1^{\circ}$ dia ao $14^{\circ}$ dia, em que o animal foi o seu próprio controle (lado direito) e o uso da pomada de copaíba no lado esquerdo. Na primeira fase, o lado esquerdo com uso de copaíba teve um rápido declínio da enduração e hiperemia local $(P<0,05)$. No lado direito sem uso de copaíba não se observou redução na velocidade de cicatrização. Do $1^{\circ}$ ao $14^{\circ}$ dia , não foi observada diferença estatística entre o lado tratado com copaíba e o lado não tratado, para os parâmetros de vascularização, fibrose, fibroblastos, neutrófilos, linfócitos e eosinófilos ( $P>0,05)$ (Figura 1 A e B).

Figura 1 - Histomorfologia - Fase 1.

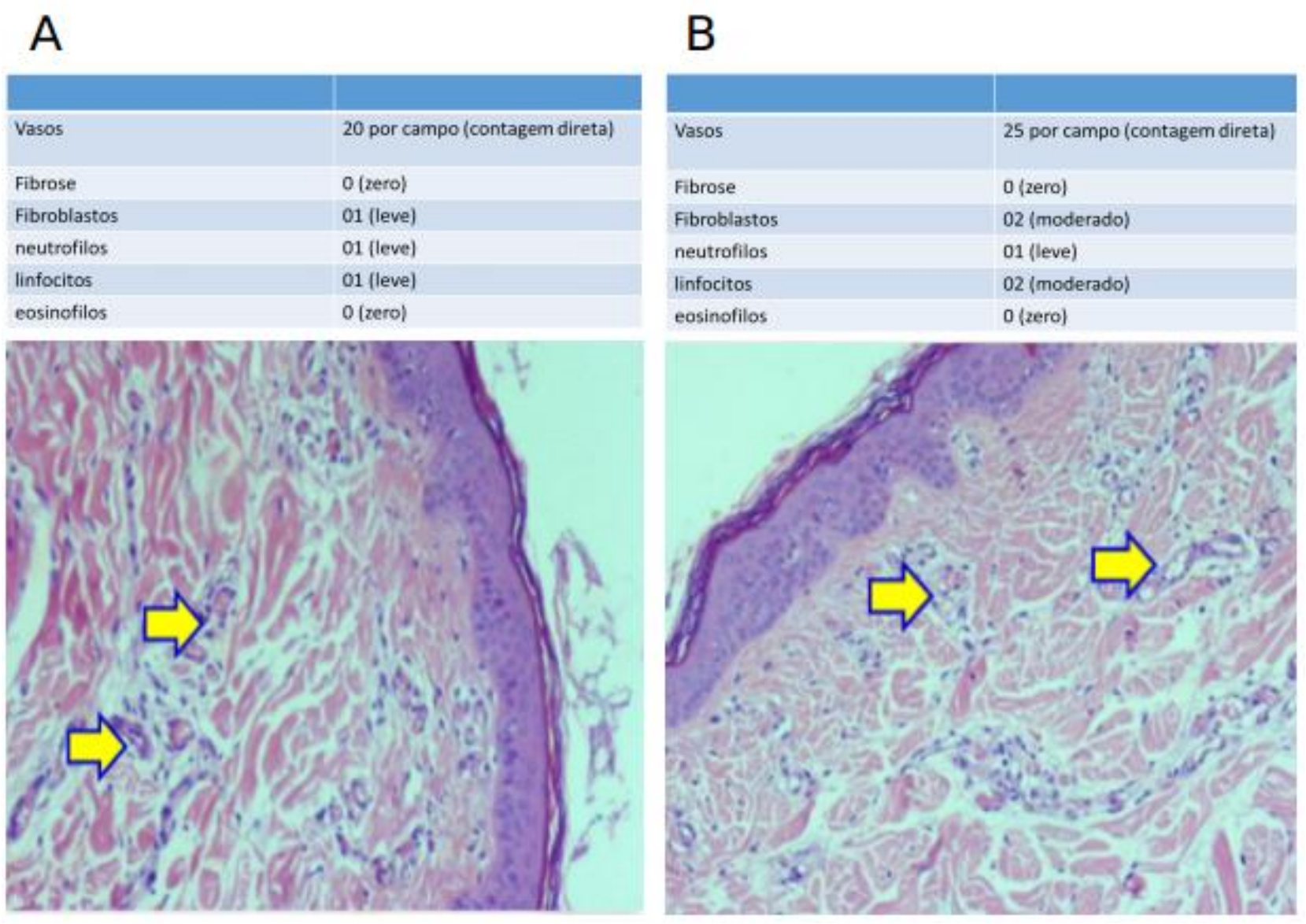

Legenda: Figuras A com copaíba e B sem copaíba: pele exibindo na derme proliferação vascular (HE, 100x).

Fonte: Cansian JA, et al., 2020. 
$\mathrm{Na}$ fase dois do experimento, os animais evoluíram clinicamente bem e sem intercorrências. No décimo quinto dia do experimento a área endurecida e hiperemiada diminuíram, e no décimo oitavo dia a enduração e hiperemia estavam reduzidas em $50 \%$. No $21^{\circ}$ o edema e hiperemia praticamente reduziram a meio centímetro.

Na segunda fase, no lado esquerdo com uso de copaíba ocorreu uma rápida redução da enduração e hiperemia em relação ao lado direito sem uso de copaíba e quando comparado com a fase 1 . Além disto, na fase 2 , foi observada uma menor proliferação no número de vasos sanguíneos e de fibrose $(P<0.02)$ no lado tratado com copaíba, quando comparada com o lado controle $(P<0.003)$.

No entanto, o lado tratado apresentou uma maior contagem de eosinófilos $(P<0.004)$ e neutrófilos $(P<0.01)$. Não foram observadas diferenças entre o número de fibroblastos e de linfócitos entre os dois grupos

(Figura 2A e 2B).

Figura 2 - Histomorfologia - Fase 2.

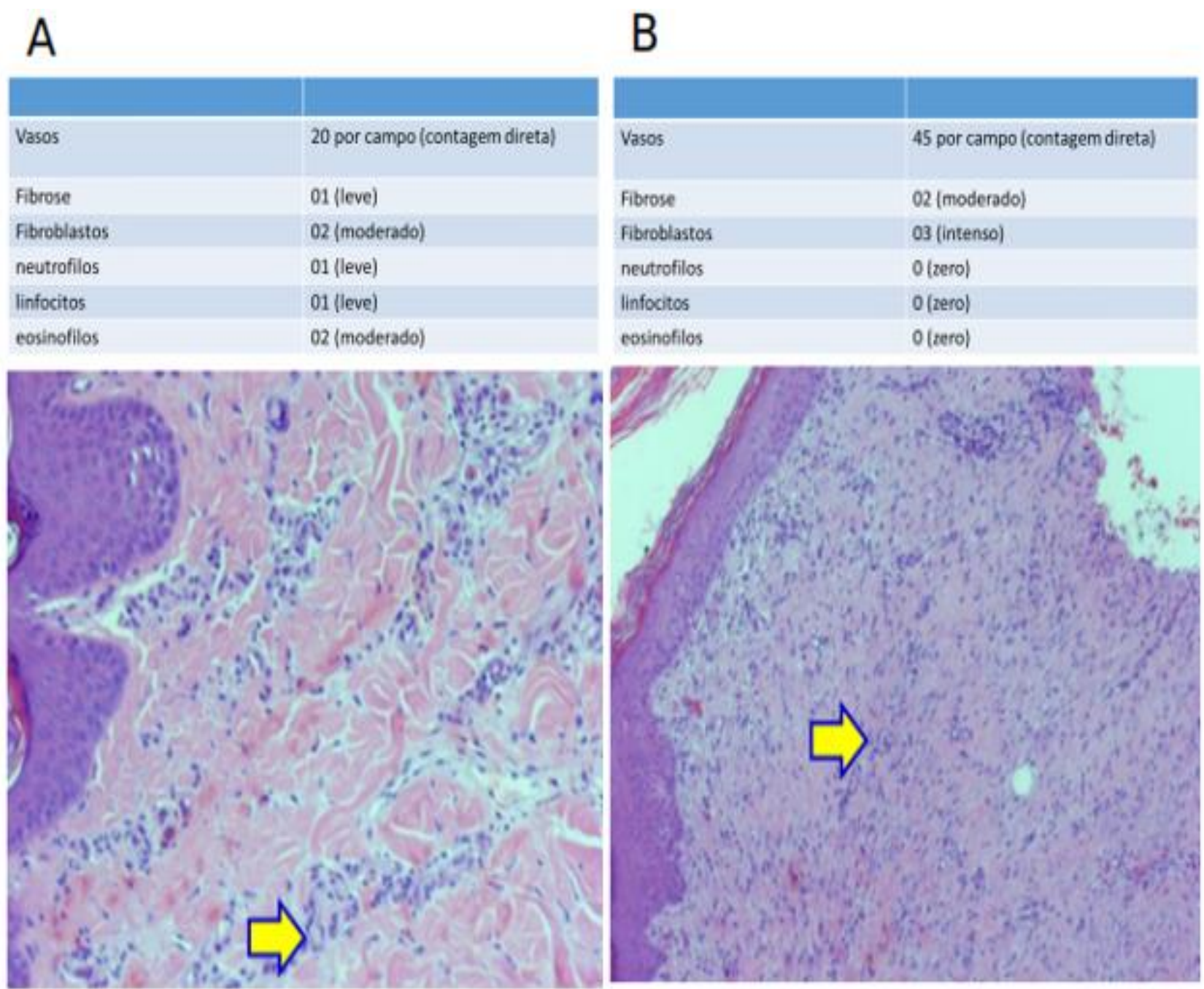

Legenda: Figura A com copaíba indicando proliferação vascular com infiltrado inflamatório (seta) (HE, 100X) e B sem copaíba indicando proliferação vascular com fibrose e infiltrado inflamatório (seta) (HE, 50X).

Fonte: Cansian JA, et al., 2020.

Durante a segunda fase, em relação as células inflamatórias (eosinófilos e neutrófilos) encontrou-se aumento no tecido com o uso da pomada de Copaíba $(P<0,004)$. O uso da pomada de Copaíba também reduziu a fibrose tecidual $(P<0,020)$ (Tabela 1$)$. 
Tabela 1 - Resultados da análise da estatística, comparando o uso da pomada de Copaiba ou não na fase 1 e 2. NS - Não significativo.

\begin{tabular}{|l|c|c|c|}
\hline & 1a fase & 2a fase & aumento \\
\hline Vasos & NS & 0,003 & Sem copaíba \\
\hline Fibrose & NS & 0,020 & Com copaíba \\
\hline Esinófilos & NS & 0,004 & Sem copaíba \\
\hline Neutrófilos & NS & 0,010 & Sem copaíba \\
\hline Plasmócitos & NS & 0,050 & Sem copaíba \\
\hline Fibroblastos & $N S$ & $N S$ & NS \\
\hline Edema & $N S$ & $N S$ & NS \\
\hline
\end{tabular}

Fonte: Cansian JA, et al., 2020.

\section{DISCUSSÃO}

A cicatrização tecidual é um processo físico, químico e biológico que se inicia logo após uma lesão tecidual, quer seja acidental ou cirúrgica e que tem por finalidade reconstruir os tecidos da melhor maneira possível (ALMEIDA MR, et al., 2012).

A microdermoabrasão (resurfing) é uma lesão superficial de pele usada comumente como uma técnica fácil de ser executada em áreas complexas, por apresentar benefícios satisfatórios em cicatrizes e manchas, não necessitando de cirurgias complexas ou uso de anestésicos tópicos, podendo ser realizada por pessoas treinadas a um baixo custo (YAMAGUCHI MH e GARCIA RF, 2012).

A reparação tecidual em decorrência a uma lesão cirúrgica, pode apresentar diferentes fases de evolução, associadas ao processo inflamatório, formação de tecido de granulação e estruturação da matriz e remodelação (MARTINI CAN, et al., 2016). Consequentemente a busca para melhorar a eficiência e a rapidez do processo cicatricial é constante.

A pomada de copaíba tem sido amplamente usada como terapia anti-inflamatória e cicatrizante por aborígenes na região da Amazônia legal há muito tempo (CHISAKI A, et al., 1964). Entretanto, não existem estudos até o presente momento sobre o uso da pomada de copaíba $20 \%$ em pele de animais suídeos submetidos a microdermoabrasão e biopsia por punch.

Artigos como de PALHETA et al. (2017) sobre microagulhamento e uso de óleo de copaíba em 14 e 30 dias, relatam um aumento de fibras colágenas, fibroblastos e vasos sanguíneos e linfáticos da pele de ratos. Relatam que a injuria provocada por microagulhas desencadeiam processo de reparação e liberação de fator de crescimento vascular, proliferando fibroblastos, síntese de colágeno e neoangiogênese, mas não relata estudos com dermoabrasão e punch em pele de suínos (LIMA EVA, et al., 2013). MARTINI CAN, et al., (2016) observaram granulação tecidual, fibras de colágeno e neoangiogênese em retalhos de ratos tratados com Copaiba langsdorffi.

As propriedades terapêuticas da pomada da copaíba são atribuídas ao dipterpenos e septirpenos pouco estudados atualmente (LEANDRO LM, et al., 2012). Acredita-se também que atuem diminuindo o oxido nítrico alterando a cadeia de reação inflamatória (CAVALCANTI BC, et al., 2006).

No decorrer do nosso experimento, verificamos uma melhora e maior rapidez de resposta inflamatória clínica com o passar dos dias com o uso de copaíba após o trauma por microdermoabrasão e punch, devido ao processo de reparo cicatricial. A pomada de copaíba agiu possivelmente na diminuição dos efeitos nocivos da cadeia de reação inflamatória, por mecanismos ainda pouco conhecidos, mas provavelmente relacionados a diminuição da produção de oxido nítrico intracitoplasmático (VEIGA-JUNIOR VF, et al., 2001; SANTOS AO, et al., 2013). Assim, a regeneração da pele e tecidos subcutâneos ocorreram de forma mais rápida, contribuindo decisivamente para apressar a velocidade de cicatrização local, como pode ser observado na (Tabela 1). 
Nosso modelo experimental utilizamos suínos, devido à sua grande proximidade morfoestrutural com os seres humanos, pelo manejo, acomodação e facilidade de manipulação. Os suínos têm sido amplamente utilizados como modelo animal, sendo usados no mundo todo (WALTERS EM e PRATHER RS, 2013). A utilização de animais oriundos do mesmo acasalamento, teve como objetivo a minimização da variabilidade genética individual entre os animais reduzindo assim o efeito da genética na resposta individual dos animais.

A dermoabrasão realizada em nosso experimento, foi conduzida com o uso de uma lixa, após a tricotomia, não causando nenhum desconforto e nenhuma complicação secundária nos animais. A escolha do uso da região cervical lateral dos animais, se deu em decorrência de ser um local onde o suíno não tem acesso para se automutilar, caso tivesse ocorrido alguma reação ou desconforto.

Os efeitos benéficos observados em nosso estudo, com o uso da pomada de copaíba $20 \%$ podem ter a mesma aplicabilidade quando usado em tecidos de pele de humanos, visto a grande similaridade entre a histomorfologia de tecidos de suínos com o dos humanos (SWINDLE MM, 2015; ERICSSON AC, et al., 2013). Com isso, o uso da pomada de copaíba poderá enriquecer as pesquisas que visam a diminuição da reação inflamatória e o aumento da rapidez da regeneração tecidual, em estudos humanos.

A dermatologia cirúrgica e os procedimentos minimamente invasivos feitos por esteticistas e profissionais de saúde poderão se beneficiar com a utilização da pomada de copaíba $20 \%$, um fitoterápico simples e de baixo custo para os profissionais e população. Estudos adicionais devem ser realizados e encorajados com 0 objetivo de melhorar a cicatrização de ulceras e feridas da pele (GONÇALVES O, et al., 2011).

Na primeira fase do nosso estudo pôde-se constatar que não houve diferença entre os lados tratados e não tratados com Copaíba. No entanto, histologicamente, houve um padrão não linear quanto ao processo de reparação da ferida entre os grupos, aonde o lado tratado com Copaíba após a dermoabrasão teve uma rápida melhora clínica nos primeiros três dias com redução em mais de $50 \%$ do tamanho da enduração e também na hiperemia local, devido à grande velocidade da reação inflamatória proporcionada pela pomada de copaíba $20 \%$ na derme de suínos.

Do quarto dia até o decimo dia ocorreu melhora de mais de $50 \%$ no edema e na hiperemia melhora em menos de 6 dias em um total de $75 \%$ do tamanho da lesão inicial. Ao final do decimo terceiro dia, a tumoração ficou em meio centímetro de diâmetro e a hiperemia inexistente.

O controle do lado direito sem copaíba demostrou não ter melhorado morfometricamente a velocidade de cicatrização, pois seguiu coma reação inflamatória normal e não influenciou na regeneração tecidual servindo de base e controle absoluto do programa.

A histomorfologia da primeira fase no lado esquerdo e no direito foi realizada no decimo quarto dia. A neoangiogênese vascular estava diminuída em relação ao controle do lado direito sem copaíba. A ação antiinflamatória da copaíba inibiu a angiogênese e consequentemente reduziu a presença de vasos e microcapilares nas biópsias do lado submetido a tratamento. Este fato indica um possível prejuízo no uso da pomada de Cobaíba no sucesso de implantes de retalhos miocutâneos que necessitam uma maior microvascularização.

O lado sem o uso de Copaíba apresentou uma maior proliferação de vasos sanguíneos quando comparado com a região tratada com Copaíba, ressaltando a ação anti-inflamatória da copaíba, fator crucial na quarta etapa da cicatrização normal onde ocorre a remodelagem do tecido e produção de colágeno (MARTINI CAN, et al.,2016; BRITO NMB, et al., 2000; WHITNEY J, et al., 2006).

No entanto teve um aumento na proliferação de fibroblastos no lado tratado quando comparado com o lado não tratado. O edema periférico da lesão foi inalterado nos dois lados, corroborando com os achados morfométricos do decimo quarto dia (Figura 1A e B).

Na segunda fase do experimento, foi observada uma proliferação de vasos sanguíneos mais intensa no lado não tratado quando comparado com o uso de Copaíba, indicando a ação inibitória da Copaíba na angiogênese vascular em lesões dermais abrasivas. No entanto foi observada uma melhora na velocidade de recuperação e redução do processo infamatório, caracterizado pela proliferação de células de defesa (Figura $2 \mathrm{~A}$ e B). 
A diminuição da proliferação inflamatória, pode ser consequência da diminuição da vascularização local, reduzindo assim a migração de células inflamatórias como mastócitos e macrófagos. O lado tratado com copaíba apresentou uma menor quantidade de fibroblastos e uma redução na fibrose tecidual, proporcionando uma melhor remodelação tecidual. Possivelmente esta regeneração foi mais uniforme com uma menor retração cicatricial, auxiliado pela síntese do colágeno e miofibroblastos estimulados pela Copaíba (BRITO NMB, et al., 2000).

Os resultados do uso da copaíba para a regeneração tecidual são bastantes divergentes na literatura e, portanto, devem ser avaliados com cuidado, especialmente em decorrência da grande variabilidade na manipulação para a produção dos cremes/pomadas bem como as diferentes formas de apresentação. Além disso é necessário a caracterização prévia dos componentes existentes na Copaíba para a sua aplicabilidade. No entanto, o efeito do uso da Copaíba mais marcante em nosso experimento, foi a supressão da vascularização sanguínea, o que resultou na diminuição do processo inflamatório local, potencializando assim a regeneração tecidual, minimizando a fibrose tecidual melhorando assim o processo cicatricial.

\section{CONCLUSÃO}

O efeito da pomada de copaíba $20 \%$ na regeneração tecidual da pele de suínos apresentou significativa melhora clínica nas duas fases do experimento, aumentando a velocidade da reação inflamatória, com diminuição da tumoração e da hiperemia, estimulando a formação de fibrose, a produção de colágeno e o aumento das células inflamatórias, propiciando rápida velocidade na reação cicatricial local. A pomada de copaíba $20 \%$ pode ser usada em lesões superficiais envolvendo epiderme, derme e tecido celular subcutâneo, até atingir a fascia superior muscular. Visto que a pele de suínos é semelhante ao de humanos, o estudo poderá servir de base no auxílio de fechamentos cutâneos simples e complexos, de escoriações dérmicas e até de retalhos cutâneos epidérmicos e subdérmicos randomizados em humanos.

\section{REFERÊNCIAS}

1. ALMEIDA MR, et al. Genotoxicity assessment of Copaiba oil and its fractions in Swiss mice. Genet Mol Biol. 2012; 35(3): 664-72.

2. AMORIM JL, et al. Wound healing properties of Copaifera paupera in diabetic mice. PLoS One. 2017; 12(10): 1-14.

3. BRITO NMB, et al. Aspectos morfológicos, morfométricos e imunohistoquimicos pelo PCNA, no colo uterino de ratas ooforectomizadas, após aplicação do óleo de copaíba. Acta Cir Bras. 2000; 15(1): 41.

4. CASCON V, GILBERT B. Characterization of the chemical composition of oleoresins of Copaifera guianensis Desf., Copaifera duckei Dwyer and Copaifera multijuga Hayne. Phytochemistry. 2000; 55(7): 773-8.

5. CAVALCANTI BC, et al. Genotoxicity evaluation of kaurenoic acid, a bioactive diterpenoid present in Copaiba oil. Food Chem Toxicol. 2006; 44(3): 388-92.

6. CHISAKI A, et al. O isolamento e na vivo atividade anti-tumoral potente diterpenoide de clerodânicos da oleoresina da planta medicinal brasileira, langsdorffi Copaífera Deston. Bloorg Med Chem Left. 1964;4:2889-92.

7. DIAS-DA-SILVA MA, et al. The influence of topic and systemic administration of copaiba oil on the alveolar wound healing after tooth extraction in rats. J Clin Exp Dent. 2013; 5(4): 169-73.

8. ERICSSON AC, et al. A brief history of animal modeling. Mo Med. 2013; 110(3): 2015.

9. ESTEVÃO LRM, et al. Neoangiogênese de retalhos cutâneos em ratos tratados com óleo de copaíba. Pesq Aagropec Bras. 2009; 44(4): 406-12.

10. GONÇALVES O, et al. Evaluation of the mutagenicity of sesquiterpenic compounds and their influence on the susceptibility towards antibiotics of two clinically relevant bacterial strains. Mutat Res. 2011; 723(1): 18-25.

11. GUSHIKEN LFS, et al. Skin Wound Healing Potential and Mechanisms of the Hydroalcoholic Extract of Leaves and Oleoresin of Copaifera langsdorffii Desf. Kuntze in Rats. Evid Based Complement Alternat Med. 2017; 2017: 1-16.

12. LEANDRO LM, et al. Chemistry and biological activities of terpenoids from copaiba (Copaifera spp.) oleoresins. Molecules. 2012;17(4): 3866-89.

13. LIMA EVA, et al. Microagulhamento: estudo experimental e classificação da injúria provocada. Surgical and Cosmetic Dermatology. 2013: 5(2): 110-114.

14. MARTINI CAN, et al. Análise comparativa dos efeitos do óleo-resina de Copaifera multijuga e da nitrofurazona na cicatrização de ferida cutânea. Rev. Col. Bras. Cir. 2016: 43(6): 445-451. 
15. MARTINS-DA-SILVA RCV, et al. O gênero Copaifera (Leguminosae - Caesalpinioideae) na Amazônia brasileira. Rodriguésia. 2008; 59(3): 455-76.

16. PAIVA LA, et al. Investigation on the wound healing activity of oleo-resin from Copaifera langsdorffi in rats. Phytother Res. 2002; 16(8): 737-9.

17. PALHETA CSA, et al. Efeito do óleo de copaíba associado ao microagulhamento na pele de ratos: um estudo comparativo. Surg Cosmet Dermatol. 2017; 9(4): 289-94.

18. SANTOS AO, et al. Antileishmanial activity of diterpene acids in copaiba oil. Mem Inst Oswaldo Cruz. 2013; 108(1): 59-64.

19. SOUZA BARBOSA PC, et al. Phytochemical fingerprints of copaiba oils (Copaifera multijuga Hayne) determined by multivariate analysis. Chem Biodivers. 2013; 10(7): 1350-60.

20. SWINDLE MM. Techinical bulletins: Anesthesia and Analgesia in Swine. Handling; 2015.

21. VEIGA JUNIOR VF, et al. Chemical composition and anti-inflammatory activity of copaiba oils from Copaifera cearensis Huber ex Ducke, Copaifera reticulata Ducke and Copaifera multijuga Hayne- a comparative study. J Ethnopharmacol. 2007; 112(2): 248-54.

22. VEIGA-JUNIOR VF, et al. Phytochemical and antioedematologic studies of comercial copaíba oils avaliable in Brazil. Phytother Res. 2001; 15(6): 476-80.

23. WALTERS EM, PRATHER RS. Advancing swine models for human health and diseases. Mo Med. 2013; $110(3)$ : $212-$ 5.

24. WHITNEY J, et al. Guidelines for the treatment of pressure ulcers. Wound Repair Regen. 2006; 14(6): 663-79.

25. YAMAGUCHI MH, GARCIA RF. Copaiba oil and its medicinal properties: a bibliographical review. Rev Saúde Pesq. 2012; 5(1): 137-46. 